DOI - 10.53571/NJESR 2021.2.9.13-20

\title{
PUBLIC ADMINISTRATION WITH A GLOBAL PERSPECTIVE N.M.Kanakane
}

Department Of Political Science

Anjuman College

Darwad

nmkanakane99@gmail.com

\begin{abstract}
Globalization has been testing the hypothesis and practice of Public Administration at an exceptional level. Significant strategy issues cross public limits can't be tackled without worldwide coordinated effort-even home grown issues will be better perceived and tended to with a worldwide viewpoint. To propel Public Administration hypothesis building, we need to look at issues across public and ethno segment divisions to more readily comprehend and clarify setting specific marvels. To guarantee Public Administration's pertinence to rehearse, we should contact the worldwide policy implementation local area in scholastic trades, worldwide development and dispersion of best practices, and collective schooling. In the Minnow stream soul, we advocate pushing toward "Public Administration with a Global Perspective" (PAGP) to deliver our instructing, exploration, and commitment more applicable to the changing truth of globalization. PAGP stresses serving a worldwide local area by building speculations that offer more prominent illustrative force, have higher worthiness, and are more receptive to the requests in assorted and specific settings.
\end{abstract}

\section{INTRODUCTION}

The quest for pertinence has been an enduring topic at the Minnow stream gatherings. As an interdisciplinary applied field, Public Administration1should foster speculations valuable for the two researchers and experts to remain pertinent. In the 21 st century, basic public issues are progressively related across public limits. The generally US-arranged Public Administration is as of now not satisfactory, nor is the customary relative Public Administration. In the Minnow creek soul, we advocate "Public Administration with a Global Perspective" (PAGP) to propel information building, address reasonable is-sues, further develop Public Administration training, and, at last, increment the importance of the field. 
PAGP stresses hypothesis constructing that spans "particularize" and "widespread ism," taking care of perceptions in specific ethnic, social, and political settings, while simultaneously searching for more noteworthy informative force, more extensive viable ramifications, The quest for significance has been an enduring topic at the Minnow stream meetings. As an interdisciplinary applied field, Public Administration ought to foster hypotheses valuable for the two researchers and experts to remain important. In the $21 \mathrm{st}$ century, basic public issues are progressively associated across public limits. The generally US-situated Public Administration is presently not sufficient, nor is the conventional similar Public Administration. In the Minnow creek soul, we advocate "Public Administration with a Global Perspective" (PAGP) to propel information building, address viable issues, further develop Public Administration training, and, eventually, increment the importance of the field. PAGP stresses hypothesis assembling that spans "particularize" and "universalism," taking care of perceptions in specific ethnic, social, and political settings, while simultaneously searching for more prominent informative force, more extensive reasonable ramifications,

\section{GLOBAL CHALLENGES DEMANDING A GLOBAL PERSPECTIVE}

The world has progressively been incorporated and changed through the course of globalization in late many years. The effect of globalization on policy implementation and administration has evoked different reactions both mentally and essentially. Basic public issues are progressively related across public limits (Robertz2004). A huge range of arising issues, for example, antiterrorism wars, normal and human catastrophes, plague sicknesses, monetary emergencies, energy and natural issues, and ethnic conflicts, are generally internationally interconnected. Indeed, even issues inside the conventional homegrown strategy domains, like public transportation, data the board, and guard and security, have been moved across public limits by expanded privatization and con-tracting endeavors, requesting worldwide points of view in building information and looking for arrangements. Such issues in the open arena present difficulties to the regularly US-driven Public Administration hypotheses and practices. We need another hypothetical point of view of Public Administration that accepts the chance to learn at the worldwide level. The rise of another world request showed by the rising force of the European Union and momentary/creating economies recommends the deficiency and obsolesce of the Public Administration structure dominatingly dependent on US encounters. Disappointment over the 
ethnocentric and parochial nature of American Public Ad-ministration has been all around communicated in the writing (Heady 1995; Hood 1989). US-driven Public Administration was not considered by numerous individuals as either educational or relevant to non-western countries. Non-western states and the European people group have investigated commonsense arrangements and created important illustrations that ought not be overlooked by the standard Public Administration writing. The undeniably incorporated and animated European people group challenge the main situation of the United States in Public Administration hypothesis building and work on improving. The broad experience of the previous Soviet managerial frameworks taking a stab at popular government and free enterprise is important to other momentary or nondemocratic states in Asia, South America, and Africa. The plentiful information from E-government improvement in Singapore, Hong Kong, and Korea significantly supplements the US and European encounters. The examples of overcoming adversity of China's financial improvement zones along its beach front regions additionally illuminate a large number of the bothered western economies. Russia, China, and other temporary majority rule governments can gain from free enterprise and policy implementation in Westminster nations similarly as the present and future public heads in America and Europe can gain from the developments of China, India, Korea, and different nations.

\section{ELIGIBILITY CRITERIA}

During the time spent fostering the qualification standards for the review, a few key terms require definition. By and large, the field is worried about "... the act of including individuals from general society in the plan setting, dynamic, and strategy shaping exercises of associations/organizations answerable for strategy advancement" (Rowe and Frewer, 2005, p. 253). The expansive definition prompts a wide exhibit of operationalizations and measures, as will be shown and are remembered for the orderly survey. Be that as it may, a clarification for commitment contrasted and investment and why both may be remembered for the review is important. The writing will in general recognize these ideas by the degree and force of the inclusion of the general population (Arnstein, 1969). Commitment alludes to more aloof systems, like imparting data to the general population or counseling inclinations (Lukensmeyer and Torres, 2006). Conversely, interest requires broad freedoms for exchange and pondering or people in general being a piece of the arrangement or activity of the help, additionally called coproduction (Bovaird, 2007). In spite of qualification in wording, both 
commitment and support require actuation of the public's premium and hence are remembered for the review and results with respect to persuasive elements are summed up to the two regions to gain from a more extensive cluster of studies.

\section{SEARCH STRATEGY}

To recognize exact investigations, looks for four points were led, "resident commitment," "resident cooperation," "public interest," and "public commitment." Both resident and public are utilized as qualifiers to attract a more extensive size of articles. Initial, three top policy implementation diaries sites were looked straightforwardly, Journal of Public Administration Research and Theory, Public Administration Review, and Administration and Society. All are in the main five rankings of policy management diaries by Bernick and Krueger (2010). Each term was looked independently, in citations, and could show up anyplace in the article. The entire years the diary was distributed were incorporated. A dominate document was utilized to enter all titles from all inquiries and used to recognize redundancies in articles returned because of utilizing various hunt terms. Then, at that point, a JSTOR search was applied utilizing a changed pursuit methodology. The JSTOR progressed search restricted the area of the pursuit terms to abstracts and utilized "or" between the hunt terms. The pursuit was likewise restricted to "articles" in thing types and English as the language. At long last, the JSTOR search was diary separated to incorporate diary titles in the JSTOR characterization of "public strategy and organization," that are additionally positioned by Bernick and Krueger (2010), and were excluded from the earlier diary explicit hunt. The diaries remembered for the JSTOR search have restricted accessibility by years as shown in enclosures, next. The diaries remembered for the JSTOR search are, Journal of Policy Analysis and Management (1981-2012), Journal of Public Policy (1981-2012), Public Administration Quarterly (19352015), Public Performance and Management Review (2000-2010), Publius (1971-2012), and State and Local Government Review (1976-2014). The pursuit measures took on guarantee that concentrates on that show up in high- quality peer-reviewed diaries are incorporated. The pursuit was restricted to policy implementation diaries in light of the fields' devotion to understanding and supporting practice. An outline of the consequences of the pursuit and screening measure are introduced in Figure.

\section{RESEARCH METHODS SURVEY}


Examination strategies are extremely well known among Social Science understudies especially connected with this discipline. A great deal of understudies likewise embrace between disciplinary investigations like including this discipline with Economics for Budgetary Planning and with Human Resource Management for Training techniques for Bureaucrats. In any case, a large portion of the examination results will in general show up at speculations which have extremely restricted applications in this subject. One more place of concern is the shortfall of any conversation between the understudies of this discipline and the experts of different disciplines of Social science to show up at a practical arrangement. The Survey techniques are swarmed with a few superfluous impacts in a muddled social framework like India thus there is a requirement for Controlled Field Experiment strategy for yielding feasible outcomes. One more methodology which is impressively unique contrasted with the Survey/talk with strategy is the assessment of changing jobs relying upon context oriented varieties. This technique clarifies a specific examination issue in a restricted way however has the ability to deliver explicit outcomes dependent on the current financial and political setting. A few new exploration procedures have advanced in this discipline with the improvement of Science and innovation, for example, Computer and Electronic Datahandling, Systems Approach and Management Science (quantitative-situated instruments) techniques. These techniques include efficient handling of data and yields more unbiased and dependable outcomes as they consider more number of significant factors. Business Management experts are concentrating on the different dynamic cycles in Public Administration as they generally affect the tremendous populace of a country. Donald Tull and Gerald Album has separated between two kinds of study techniques, the Decisional and the Basic. "While the previous study is directed to give data to settling on a forthcoming choice, the later are those concerned essentially with the progression of logical information. The fundamental distinction between the two methodologies of examination lies in the suitability of the specialist's choice in the assortment and investigation of information. A valid and acceptable fundamental review approach puts forth a genuine attempt to gather information with the goal that they might be checked impartially, the subsequent testing blunders are arbitrary, methodical mistakes are quantifiable and non-critical method for examination are taken response to. It requires principal information to plan and carry out it to create satisfactory results. Then again, an examination dependent on decisional overview approach is utilized to enhance and sometimes override these non-critical techniques. The standard in question, as material to both the exploration overall and to every component 
specifically, is to gauge esteem versus cost of data" (Tull and Album, 1973). One more type of examination strategy is to utilize numerical investigation and conduct procedures to concentrate on Bureaucratic ideas and Human Resource Development and this may be utilized by current specialists to discover answers for complex issues in this discipline. It should be referenced at this point that Public Administration, as a discipline, is so differed and its degree is enormous to such an extent that practically every one of the customary strategies for request, for example, Personal Experience, Deductive Reasoning and Empirical Observation could be applied to it yet it should be seen that such application probably won't yield ideal outcomes in all conditions as it is an exceptionally context oriented driven discipline. Lynton Cadwell has put more accentuation on two different techniques in particular Heuristic Analogy and Inductive Reference. Anyway these strategies have restricted extent of use in research approach relating to this discipline. Heuristic similarity prompts the arrangement of a social model which is utilized as a substitution for the less adequate control test, all things considered, authoritative circumstance. This similarity helps in the useful investigation of the changing examples of this discipline and furthermore discovers the answers for complex genuine circumstances looked by organization. Then again, Inductive derivation assembles its very own hypothetical model and the information on which it rests will acknowledge the goal tests. This strategy is considered as an entirely solid wellspring of research and can essentially add to this field of study. "In any case, this technique includes conceiving elective speculation, framing fitting analysis with elective result and rehashing strategies to get end or refinement of consecutive theory" (Cadwell, 1968). So it could be acknowledged at this crossroads that it is without a doubt hard for any scientist to decide the most fitting technique for the review and examination of the different exploration issues in this discipline. This is on the grounds that the techniques which are accessible for leading examination are dependent upon nonstop change in a few regions and a portion of the advanced strategies are as yet existent just in the trial stage. The circumstance is much more intricate in the Indian situation with its remarkable financial and political person which will in general forestall the set up and broadly acknowledged systems from extricating adequate outcomes.

\section{CONCLUSION}

In this way we have an exceptional situation of picking the most fitting strategy for research from the accessible information and it requires a great deal of understanding the ground truth 
of the examination issue which we need to break down. However it is consistent with some degree that this discipline depends on the accessible strategies and devices, yet it could be expressed that as a discipline, policy management has a lot more extensive extent of study contrasted with different parts of Social Science. The need of great importance is to rebuild the courses of Research philosophies in Public Administration remembering the relevant examples and the new techniques applied in research. James Charles worth had once seen that "technique in Public Administration can't be normalized and endorsed: strategy is simply the man". Along these lines, in any cutting edge society, the recipient, the average person, the laborers, the business local area, the researchers, the executives and above all, the lawmakers shape the general public we live in and it is their complicated interrelationship which at last chooses the idea of organization, the examination prospects and the exploration strategies to be applied. It is subsequently apparent that a lot of our review and progress in this discipline just as its development relies on the degree we can absorb the powerful types of the general public and the reliance of this discipline on different surges of Social Science. Alongside this angle, we need to achieve a few changes in our showing techniques from just clarifying the hypothetical parts of Research Methodology in this discipline to viable openness, for example, field outings and genuine encounters. This will empower the understudies to foster a basic comprehension of this subject and quest for sensible and attainable answers for managerial issues. There is additionally a requirement for a typical stage for every one of the famous researchers and academicians to meet occasionally and offer their discoveries and encounters on execution of Research Methodology in various cases and how far they have been effective in discovering OK outcomes which could be applied, all things considered, circumstances. Such cooperation may likewise prompt rise of novel thoughts and conceivable outcomes will improve the subject. The Government ought to use offices, for example, University Grants Commission and Indian Institute of Public Administration to facilitate among the examination researchers with the goal that any groundbreaking thought or finding at the individual or establishment level might be used at the public level to advance the discipline. Policy management, as a discipline, is one of the not very many subjects which affects the working and advancement of the State thus successful advances ought to be taken to improve the discipline, with the assistance of scientists and academicians, so it can scale the statures of dynamism and prominence which it so well merits.

\section{REFERENCES:}


1) Tull, D. S., \& Albaum, G. S. (1973). Survey research: A decisional approach. Intext Educational Publishers.

2) Nag, D. Public Administration in India: Research trends and initiatives.

3) Jain, R. B. (1977). Research methodology in Public Administration in India: A need for new orientation. The Indian Journal of Political Science, 38(2), 253-262.

4) Jones, G. N. (1982). Rise and fall of a professional ideal: Particulars concerning public administration. The American Review of Public Administration, 16(4), 305319.

5) Denhardt, R. B. (1981). Toward a critical theory of public organization. Public Administration Review, 41(6), 628-635.

6) Shafritz, J., Russell, E. W., Borick, C., \& Hyde, A. (2016). Introducing public administration. Routledge.

7) Farmer, D. J. (2015). Public administration in perspective: Theory and practice through multiple lenses. Routledge.

8) Farazmand, A. (2012). The future of public administration: Challenges and opportunities-A critical perspective. Administration \& Society, 44(4), 487-517.

9) McNabb, D. E. (2017). Research methods in public administration and nonprofit management. Routledge.

10) Henry, N. (2015). Public administration and public affairs. Routledge.

11) Legge Jr, J. S., \& Devore, J. (1987). Measuring productivity in US public administration and public affairs programs 1981-1985. Administration \& Society, 19(2), 147-156.

12) Morgan, D. R., Meier, K. J., Kearney, R. C., Hays, S. W., \& Birch, H. B. (1981). Reputation and productivity among US public administration and public affairs programs. Public Administration Review, 666-673.

13) Douglas, J. W. (1996). Faculty, graduate student, and graduate productivity in public administration and public affairs programs, 1986-1993. Public Administration Review, 433-440. 